\title{
Metapoesía y discurso amoroso en la obra de Tamara Kamenszain
}

Según Jeanne Demers, la «poética de los poetas» es un subgénero metapoético que surge en la estela del romanticismo, espoleado por el descubrimiento de la libertad del poeta en un mundo huérfano (el de los «hijos del limo» descrito por Nerval, que Paz reinterpretaría con brío), un mundo ya no regulado por una pretensión universalista y prescriptiva propia de las artes poéticas clásicas. ${ }^{1}$ Estimulados por los ejemplos de Baudelaire ${ }^{2}$ y Mallarmé, los modernistas hispanoamericanos también practican esta "poética de poetas» a la par que construyen filiaciones literarias en las que situar su propia poesía. José Martí ofrece un ejemplo emblemático de tal entrelazamiento entre crítica de la poesía ajena y definición de la poética propia en su famoso texto: el «Prólogo del «Poema del Niágara de Juan A. Pérez Bonalde» (1882).

Al practicar de modo - casi- sistemático la alternancia entre ensayos (generalmente centrados sobre la crítica de poesía) y poemarios, la escritora argentina Tamara Kamenszain (1947) se inscribe en esta tradición moderna. ${ }^{3}$ En este estudio, quisiéramos profundizar en el valor metapoético tanto de su producción ensayística como de su poesía a partir de un corpus parcial pero muy significativo. Seguiremos un plan dialéctico: en un primer momento, consideraremos un texto de juventud que plantea una especie de "poética de poetas» al definir una concepción de la creación que será válida mutatis mutandis para el conjunto de la obra poética ulterior. En un segundo momento, abordaremos dos poemarios (Tango bar y Solos y solas) que movilizan varios modelos literarios, los cuales resultan de alguna manera insuficientes para elaborar una reflexión metapoética que corres-

$1 \mathrm{El}$ «Art poétique» de Boileau sería un ejemplo paradigmático.

2 Ya Baudelaire afirmaba que «todos los grandes poetas se vuelven naturalmente, fatalmente, críticos» (Baudelaire [«Richard Wagner et 〈Tannhàuser»». dans OEuvres poétiques], citado por Jeanne Demers: «Présentation. En liberté, la poétique». In: La poétique de poète. Etudes françaises 29, 3 (1993), p. 7; traducción nuestra).

3 Kamenszain es autora de poemarios, entre ellos: De este lado del Mediterráneo (1973), Los No (1977), La casa grande (1986), Vida de living (1991), Tango bar (1998), El ghetto (2003), Solos y solas (2005), El eco de mi madre (2010). Como ensayista ha publicado El texto silencioso (1983), La edad de la poesía (1996), Historias de amor (y otros ensayos sobre poesía) (2000), La boca del testimonio (2007), Una intimidad inofensiva (2016).

Geneviève Fabry, UCLouvain

๖ Open Access. ( 2021 Geneviève Fabry, published by De Gruyter. (c) BY-NC-ND This work is licensed under the Creative Commons Attribution-NonCommercial-NoDerivatives 4.0 International License.

https://doi.org/10.1515/9783110736274-014 
ponda a la etapa vital y creativa de la autora. Finalmente veremos cómo El libro de Tamar da una vuelta de tuerca a esta búsqueda que interroga los límites de la dicción poética. De hecho, la hipótesis que subyace en este análisis estriba en la unión estrecha entre el cuestionamiento acerca de las potencialidades de la enunciación poética (¿qué puede decir el poema?) y las aporías que acechan al discurso amoroso (¿es posible expresar la experiencia viva del amor?).

\section{El texto silencioso (1983) como «poética de poetas»}

Sin ninguna duda, los primeros ensayos de Kamenszain encarnan con creces la «poética de poetas», este subgénero metapoético determinado según Demers por « la importancia [para los poetas modernos] de pensar su praxis, de situarla en el marco de una poesía por inventar, que les venga del corazón y se les pegue a la piel, de una definición abierta y múltiple y de la que ninguno podía prescindir». ${ }^{4}$ Reunidos en El texto silencioso (1983), estos textos nos hablan de una tradición de poetas que

destila[ron] una obra lenta, artesanal y de difícil traducción. Mudos, femeninos, permanecieron dentro de la casa. Imitando el trabajo artesanal de las abuelas, bordaron y cosieron un texto poco apto para el intercambio. Macedonio Fernández, Girondo, Juan L. Ortiz. . . [. . . ]. Pero si Borges funda la relación con lo extranjero, estos otros maestros, agazapados en los márgenes, encuentran su poder de fundación en esos bordes donde la página queda en blanco. Y adentro, en la trastienda del texto silencioso, un espíritu ventrílocuo trabaja: una doble voz que dice callando mientras retumba en el vientre materno. Es la misma que Lezama Lima hace oír como expresión americana. ${ }^{5}$

En este breve prólogo que antecede a los cinco $^{6}$ artículos monográficos del libro dedicados a poetas hombres, la poesía se define desde lo materno, desde la casa. Incluso en el caso de Lezama Lima, un escritor cuya «expresión americana» no sería ajena a la adopción por Kamenszain de una estética barroca, el comentario crítico se esfuerza por dilucidar el diálogo ininterrumpido que mantiene con la madre. Aparentemente, la doble voz que caracteriza a esta tradición silenciosa

4 Jeanne Demers: «Présentation», p. 8; traducción nuestra.

5 Tamara Kamenszain: Historias de amor (y otros ensayos sobre poesía). Buenos Aires: Paidós 2000, p. 171.

6 Además de los tres nombres que aparecen en la cita, hay también otros dos artículos sobre Enrique Lihn y Francisco Madariaga. 
no habla directamente de la poesía de Kamenszain. Sin embargo, Alicia Genovese ve en esta denominación una marca de fábrica de la poesía de mujeres que emerge en la Argentina «a partir de la década del 80». ${ }^{7}$ Cuando Kamenszain habla de la tradición silenciosa de ciertos poetas argentinos, habla pues también de su propia concepción y de su propia práctica de la escritura poética. La dimensión metapoética se afirma en uno de los textos finales del ensayo: «Bordado y costura del texto». Kamenszain reivindica una "vanguardia doméstica» ${ }^{8}$ en la que «la experimentación, la artesanía» es algo que «le pertenece [a la mujer] por tradición» ${ }^{9}$ ya que «Coser, bordar, cocinar, limpiar» son «maneras metafóricas de decir escribir». ${ }^{10} \mathrm{El}$ espacio doméstico se vuelve así lugar de aprendizaje de la única lengua que sirve realmente para escribir: «la lengua familiar», ${ }^{11}$ es decir, la lengua materna:

Y en el contacto con la madre es donde se desarma la frase. Su pomposidad muere con la plática, su pesadez con el cuchicheo, su amplitud con el silencio. Lugar de marginalidad y desprestigio donde la madre se comunica con su hija; allí sedimenta y crece, como una telaraña, el inmenso texto escrito por mujeres. ${ }^{12}$

Al hacer del espacio doméstico un crisol de transmisión cultural, lo transforma en una «utopía» ${ }^{13}$ en la que se invierten las marcas de desvalorización que la norma patriarcal asocia con los quehaceres femeninos en el hogar. Obviamente, Kamenszain acota aquí el espacio en el que ya ha empezado a construir su obra poética, que se vale de la relectura de la historia familiar para indicar su propio lugar de enunciación. En consonancia con esta poética del texto como herencia materna, se trata de un lugar heredado de una posición femenina en el entramado de los intercambios verbales dentro del hogar. En su primer libro de poemas, De

7 «Los nuevos textos hablan con una voz encubierta, una voz en sordina, una doble voz. La primera voz, respondiendo a las exigencias de una crítica [...], que se preocupará por el entramado del texto, por su trabajo con los procedimientos. La segunda voz, dejando en la superficie textual las marcas de un sujeto que disuelve una identidad social sobrecargada de mandatos y deberes para proyectarse en otra distinta que es básicamente reformulación. Un sujeto que niega pero también afirma [. . .]. es la voz de un sujeto que va creando un discurso al tener que reescribir y sobreescribir el discurso social que la ha marginado [. . .]» (Alicia Genovese: La doble voz: Poetas argentinas contemporáneas. Buenos Aires: Biblos 1998, p. 16).

8 Tamara Kamenszain: Historias, p. 210.

9 Ibid., p. 211.

10 Ibid., p. 208.

11 Ibid., p. 209.

12 Ibid., p. 211.

13 Alicia Genovese: La doble, p. 85. 
este lado del Mediterráneo (1973), Kamenszain define esta posición mediante la referencia al personaje bíblico de Ruth, moabita y extranjera en tierras de Israel:

En esta tristeza de no ser más la que sentándose en las rodillas de un abuelo escuchaba la historia de la moabita Ruth está la alegría de encontrar en cada objeto un indicio de esa historia, el asombro de saber que la poesía no hace más que continuarla porque es a la vez la madre y la hija de la moabita Ruth. ${ }^{14}$

En esta historia escuchada «en las rodillas del abuelo», se cruza la tradición masculina, la de la Ley y del Libro, con una historia de mujer que subraya «un determinado aspecto de la tradición judía: un vínculo [. . .] con el velo de la no pertenencia, con experiencia de la movilidad [sic], con un aspecto de la identidad que mantiene siempre abierta la cuestión de la diferencia». ${ }^{15}$ La historia de una escritura que se forja en el movimiento doble y paradójico de salida del ghetto y reinscripción sesgada en el mismo espacio simbólico es una constante que se repite en varios textos poéticos ${ }^{16}$ y metapoéticos ${ }^{17}$ de Kamenszain. En esta perspectiva, la relación entre poesía y textos metapoéticos consiste en una especie de continuum que entreteje los mismos hilos enhebrados alrededor de la cuestión de la identidad judeoargentina de una sujeta ${ }^{18}$ que escribe desde la oralidad materna, saliéndose de un ghetto marcado por la ley paterna que, sin embargo, sigue definiéndola de manera parcial.

14 Tamara Kamenszain: La novela de la poesía. Buenos Aires: Adriana Hidalgo 2012, p. 80.

15 Denise León: «La mirada de Ruth: Fabulaciones del linaje de la poesía de Tamara Kamenszain». In: Anales de Literatura Hispanoamericana 38 (2009), p. 350. La autora argentina también se refiere al personaje de Bruria. Véase el análisis de León al respecto.

16 Véase el epígrafe de El ghetto (2003): «In memoriam Tobías Kamenszain. / En tu apellido instalo mi ghetto» (Tamara Kamenszain: La novela, p. 265).

17 Un ejemplo sería el texto «El círculo de tiza del Talmud». (En El texto silencioso. Historias de amor).

18 Véase al respecto la entrevista con Nancy Fernández : «Cuando en un poema de La casa grande (1986) dije «sujeta〉 (el verso dice «se interna sigilosa la sujeta) quise sin duda hacer explícita la marca femenina, pero fíjate que el poema lo escribí en tercera persona aunque sin duda me estaba refiriendo a mí (a mi persona, digamos). En mi último libro que acaba de salir, El libro de los divanes (2014), retomo ese poema para darle otra vuelta preguntándome por qué lo escribí en tercera persona y esto es lo que me respondo: 〈Para mí lo urgente a esa edad era / graduarme de mí misma retener / como diploma de adulta mi nombre propio / en una celda impersonal»» (Nancy Fernández: «Entrevista a Tamara Kamenszain». In: Revista Iberoamericana 261 (2017), p. 737). 


\section{Alcance metapoético de la intertextualidad en Tango bar (1998)}

La escritura definida en relación con el mundo oral y femenino recibe nuevas significaciones a medida que va evolucionando la autora: se enriquece con nuevos sentidos existenciales y nuevas proyecciones intertextuales que son también maneras de armar familias literarias imaginarias, tanto desde el verso como desde el ensayo. En esta perspectiva, nos interesa ahondar en un poemario clave que complejiza la asociación entre escritura y oralidad femenina a partir de un tratamiento complejo de la intertextualidad. Se trata del libro Tango bar (1998) que contiene en su centro un «arte poética» que gira alrededor de una escritura (la de Delmira Agustini) que se nos propone como modelo, aunque sea un modelo problemático. El íncipit y el éxplicit del poemario también hacen énfasis en otras dos figuras señeras de la tradición literaria: Santa Teresa de Jesús y T.S. Eliot. Estas tres referencias intertextuales giran alrededor de las potencialidades y los límites de una enunciación femenina, o sea, llevan a problematizar lo que constituye el meollo del «texto silencioso» en el que se fragua la poesía de Kamenszain.

\subsection{La celda teresiana}

Durante los años 80 y comienzos de los 90, Kamenszain se ha afianzado como una representante de la corriente neobarroca, aclimatada en las tierras rioplatenses como poesía neobarrosa. ${ }^{19}$ Progresivamente, la exigencia formal de la sintaxis distorsionada contenida en el corset del verso regular empieza a constituir un ejercicio fácil, carente de autenticidad. En el epílogo de Medusario (1996), un texto de Kamenszain que sella una famosa antología de poesía neobarroca, no figura ninguna mujer aunque abundan las referencias masculinas. Entre ellas, es dominante el modelo gongorino: «algunos volvemos a caminar por aquella vía que Góngora trazó para el verso desde el corazón de la sintaxis». ${ }^{20}$ En este sentido es característico el trabajo del hipérbaton en La casa grande (1986), así como el

19 Retomamos aquí el término acuñado por Perlongher: «En su expresión rioplatense, la poética neobarroca enfrenta una tradición literaria hostil, anclada en la pretensión de un realismo de profundidad que suele acabar chapoteando en las aguas lodosas del río. De ahí el apelativo paródico de neobarroso para denominar esta nueva emergencia» (Néstor Perlongher: «Introducción a la poesía neobarroca cubana y rioplatense». In: Revista Chilena de Literatura 41 (1993), p. 57). 20 Tamara Kamenszain: «Epílogo»: R. Echavarren, J. Kozer y J. Sefaní (eds.): Medusario: Muestra de poesía latinoamericana. Santiago de Chile: AErea 2016, p. 421. 
énfasis en la mirada : «Vitral es el ojo dibujado, un / cuadro de interiores con ventana [. . . ]» ${ }^{21}$ reza un poema de La casa grande.

A finales de los años noventa, en este nuevo momento de su trayectoria creativa, Kamenszain invoca un modelo literario alternativo en el poema inicial de Tango bar:

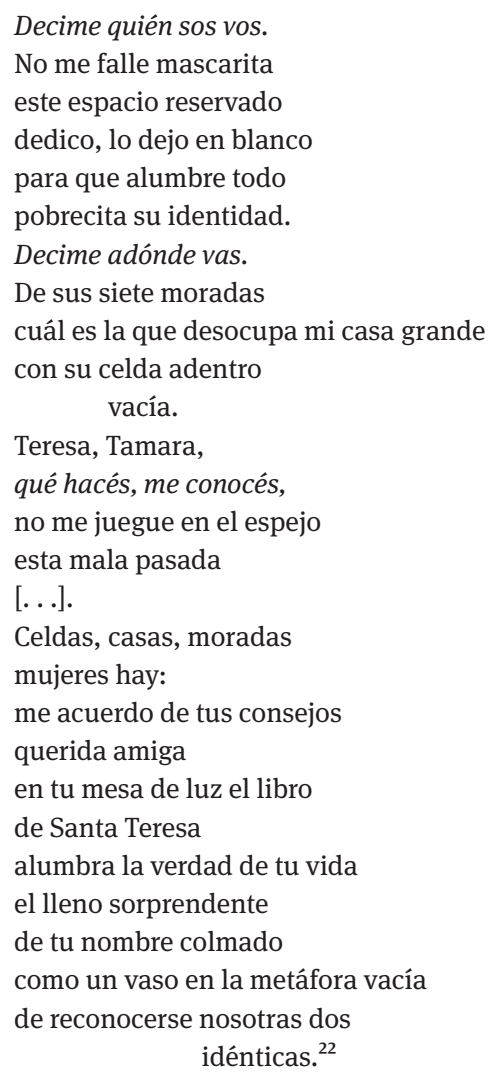

Este texto señala, en el umbral del poemario, una inflexión clave de la trayectoria de Kamenszain. La mención de «la casa grande», título del poemario publicado en 1986, ancla este poema en una mirada recapitulativa de la hablante acerca de la obra anterior. La casa grande (1986) y Vida de living (1991) transcurrían en el espacio familiar de la casa que una dicción neobarroca, ducha en la torsión sintáctica, volvía extrañamente distante. En Tango bar, lo que fue la alegoría del hogar,

21 Tamara Kamenszain: La novela, p. 174.

22 Ibid., p. 235-236. 
del amor consolidado, «la casa grande», se desplaza hacia la «celda», cuarto individual que señala sesgadamente el distanciamiento de los esposos y la búsqueda de un asidero enunciativo para el sujeto poético. La serie «Celdas, casas, moradas» entronca con la referencia a las Moradas de Santa Teresa, que viene a destacar la inflexión ya no tanto biográfica sino estética del trabajo de Kamenszain. En términos un poco abruptos, podríamos decir que pasamos, con el poemario de 1998 situado en la sombra de Teresa de Jesús, de un (neo)barroco masculino a un (pre) barroco femenino. El barroco de Santa Teresa es muy distinto del modelo gongorino. Primero es un barroco construido por la Contrarreforma y la iconografía barroca, baste con pensar en el éxtasis de la Santa esculpido por Bernini. En el ámbito argentino, a Teresa se la ve también como emblema barroco. En este sentido, es interesante subrayar que Kamenszain comienza un texto dedicado a Góngora, por una cita de Teresa, no directa, sino de la pluma de Néstor Perlongher. ${ }^{23}$ Por parte de los neobarrosos parece que Teresa es barroca por la naturalidad con la que hace parecer natural algo artificial, y al revés. En cambio, si nos referimos directamente a la obra escrita de Teresa, el brillo barroco se difumina y resalta la pregunta por la identidad que el poema enfatiza también desde los primeros versos, una pregunta más renacentista que propiamente barroca. ${ }^{24}$ Frente al hermetismo gongorino, Teresa encarna otra relación con la lengua: «una elegancia desafeitada que deleita en extremo», ${ }^{25}$ según las palabras de Luis de León, primer editor de la Madre. Luis de León se mostró muy sensible a la prosa fluida y natural de la Madre Teresa, tal vez porque él mismo intentaba hacer sonar la frescura de la lengua materna en sus propios escritos. Así justificaba el humanista el uso de la lengua vulgar para la redacción de De los Nombres de Cristo, comparándose con los Padres de la Iglesia quienes, como él, escribieron en la lengua de su madre:

[los sanctos Basilio y Chrysóstomo y Gregorio Nazianzeno y Cyrillo, con toda la antigüedad de los griegos,] en su lengua materna griega que, quando ellos bivían, la mamavan con

23 Kamenszain comienza un texto titulado «De noche, Góngora» al referirse al epígrafe de Aguas aéreas de Néstor Perlongher que es una cita de Santa Teresa de Jesús (Tamara Kamenszain: Historias, p. 121). La concatenación de las referencias es buena muestra de la deriva que sufre la categoría del barroco en Kamenszain.

24 Lo que desvela Teresa de Jesús, según Denis Vasse (L'autre du désir et le Dieu de la foi: lire aujourd'hui Thèrése d'Avila. Paris: Seuil 1991), es la hondura del enajenamiento en el que el sujeto queda apresado a causa de la dependencia de las imágenes a las que nos reenvían los demás: es lo que está en juego en lo que Teresa llama «pundonor», un punto que cristaliza la servidumbre del sujeto a lo que no es su identidad profunda sino una mera construcción social que el orgullo alienta (Vida XXXI, Santa Teresa de Jesús: Obras, p. 20). Santa Teresa propone, según Vasse, un camino de liberación frente a estas imágenes.

25 Santa Teresa de Jesús: Obras completas. Madrid: BAC 1986, p. 15. 
la leche los niños y la hablavan en la plaça las vendederas, escrivieron los mysterios más divinos de nuestra fe. ${ }^{26}$

Para fray Luis, la lengua materna es la lengua de los intercambios, sean alimenticios, comerciales o afectivos. Esta lengua marcadamente oral y afectiva es también la que funda una escucha plena y carnal. Valga este breve ex-cursus para apuntar que la referencia a Teresa le permite a Tamara definir la evolución de su lenguaje creador marcado ya no tanto por un trabajo sobre la sintaxis y la mirada (que sería propia de un libro como La casa grande), sino por el entretejimiento de las hablas que deja aflorar la lengua materna (tan presente desde el principio en Kamenszain). El eje organizador de la escritura ya no giraría alrededor de una alegoría de la casa como lugar de «sujeción», ${ }^{27}$ sino del descubrimiento de una enunciación menos teatralizada (Los No) o visualizada (La casa grande) que encarnada, hecha cuerpo, mediante el baile, el tango. La presencia central del baile de pareja y del desencuentro amoroso en el poemario hace necesario recurrir a otro modelo intertextual para pensar la escritura en clave de mujer en este contexto.

\title{
2.2 Delmira Agustini y la enunciación bisexual
}

En la segunda parte del libro, situado pues en su centro, aparece un poema especialmente interesante en nuestra perspectiva ya que se presenta explícitamente como «arte poética». Merece la pena citarlo in extenso.

\author{
Ven, oye, yo te evoco, \\ extraño amado de mi musa extraña \\ te llamo en masculino me apropio \\ de la vida de los dichos nuestros \\ me puedo escribir \\ los versos más tristes esta noche \\ te puedo decir mi musa \\ y no suena extraño. \\ Es mi «arte poética».
}

26 Fray Luis de León: De los nombres de Cristo. Madrid: Cátedra 1986, p. 496.

27 Remitimos aquí al doble sentido empleado por Judith Butler en Mecanismos psíquicos del poder. Teorías sobre la sujeción: «la sujeción es el proceso de devenir subordinado al poder, así como el proceso de devenir sujeto» (Judith Butler: Mecanismos psíquicos del poder. Teorías sobre la sujeción. Madrid: Cátedra 2001, p. 12). 


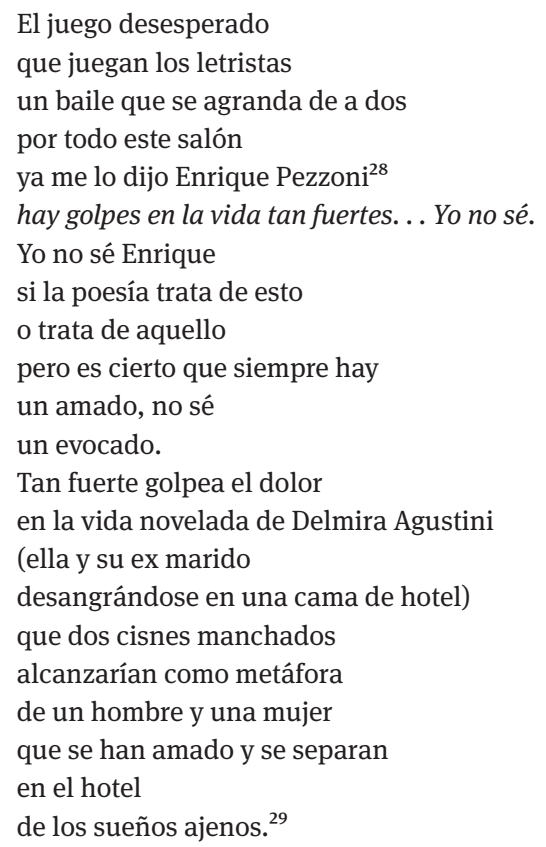

El denso entramado intertextual esboza un «arte poética» que es menos normativa que auto-explicativa. Dos versos de Delmira Agustini -elegidos por la autora como epígrafe del poemario entero- constituyen su puntal: «Ven, oye, yo te evoco, / extraño amado de mi musa extraña» (cursivas de la autora). Este dístico se repite cuatro veces en el poema «Misterio: ven» ${ }^{30}$ en el que la hablante poética parece intercambiar los roles tradicionales: el personaje masculino, al pulsar «la lira del silencio», encarnaría el polo mudo, verdadero homme fatal inspirador de la poeta.

En un ensayo recogido en Historias de amor, ${ }^{31}$ Kamenszain destaca lo que la atrae en el delicado quiasmo de la uruguya: el «extraño amado» es «un masculino que, transformado en musa de escritora, se feminiza, se extraña de sí mismo. En esta operación bisexual deviene Eros con mayúscula [. . . ]». ${ }^{32} \mathrm{Si}$ bien el poder

28 Enrique Pezzoni (25 de febrero de 1926, Buenos Aires - 31 de octubre de 1989) fue un poeta, profesor, crítico literario, escritor y traductor argentino.

29 Tamara Kamenszain: La novela, p. 255.

30 Delmira Agustini: Los cálices vacíos. Sevilla: Point de Lunettes 2013, p. 274-275.

31 Kamenszain lo termina de escribir el 31 de diciembre de 1999 (Tamara Kamenszain: Historias, p. 11), o sea que es casi contemporáneo del poemario Tango bar, publicado en 1998.

32 Tamara Kamenszain: Historias, p. 22. 
de la musa puede transitar sin problema de lo masculino a lo femenino y la autoridad falocrática de Neruda puede ser «apropiada», ${ }^{33}$ esto es, cancelada en unas pocas palabras contundentes, ¿qué hacer con el drama de amor? La «operación bisexual» agustiniana potencia el verbo poético pero abre un sinfín de interrogantes cuando se trata de hablar del amor. En primer lugar, es obvio el vínculo fuerte entre Eros y Thanatos en la poética agustiniana: «Ven, tú, el que imprime un solemne ritmo / al parpadeo de la tumba helada!», ${ }^{34}$ rezan otros versos del mismo poema. Más fundamentalmente, la experiencia amorosa queda inalcanzable en Delmira Agustini, sepultada debajo de la «vida novelada» y los «cisnes manchados [.. .] como metáfora», así como debajo de las múltiples máscaras que despliega ante sus lectores: las de la nena, de la escritora genial o de la femme fatale. Ana Peluffo sostiene que en Agustini la pose de femme fatale, consciente de su papel y activa en la relación erótica, constituye un intento de salir de la tensión que atraviesa la estética del fin de siglo XIX entre sentimentalismo y decadentismo: ${ }^{35}$ «la pose de Salomé le sirve a Agustini para contrarrestar la máscara de la nena; para colocar al sujeto masculino en el rol pasivo de musa decapitada, reservándose para sí la posición de sujeto; y para alejarse de una literatura sentimental que ya se empieza a pensar como anacrónica en las culturas de fin de siglo». ${ }^{36}$ De alguna manera, el reto que se le presenta a Tamara Kamenszain es análogo al de Delmira, salvo en una coordenada fundamental, esto es, ¿cómo situarse como sujeto en una poesía amorosa sin caer en el sentimentalismo, por un lado, pero sin volver al decadentismo?, es decir, ¿cómo desvincular el nexo entre amor y muerte?

A lo largo del siglo XX decayó nítidamente un discurso amoroso que en Occidente había vinculado estrechamente Eros y Thanatos, como lo demostró el ensayo de Denis de Rougement: L'amour et l'Occident. de Rougement sostiene que el mito amoroso fundador de Occidente es el de Tristan e Isolda. En la estela de estos amantes, la literatura occidental, desde Romeo y Julieta hasta Madame Bovary, habría celebrado el amor como búsqueda fascinada no por el otro, sino por la historia de amor en sí, historia que culmina en la muerte, siendo esta el obstáculo mayor a la pasión y por ende, su estímulo más preciado. En esta

33 Se habrán reconocido dos versos de Los veinte poemas de amor y una canción desesperada: «me puedo escribir / los versos más tristes esta noche».

34 Véanse los versos siguientes: «el que dictas los lúgubres acentos / del decir hondo de las sombras trágicas. / Ven, tú, el poeta abrumador, que pulsas / la lira del silencio: la más rara!» (Agustini, Los cálices, 274).

35 Ana Peluffo: «De todas las cabezas quiero tu cabeza»: figuraciones de la femme fatale en Delmira Agustini». In: Chasqui 34, 2 (2005), p. 132.

36 Ibid., p. 142. 
perspectiva, es interesante notar que según la socióloga Eva Illouz el nexo entre amor y dolor típico del discurso amoroso romántico (como versión aligerada del mito) se deshace en las segunda y tercera décadas del siglo XX, como evidencian los principales discursos sociales en EE.UU. estudiados por Illouz (prensa del corazón, publicidad, películas, etc.). ${ }^{37}$ A partir de los años sesenta, aproximadamente, en la extendida paleta de poéticas amorosas que surgen en Occidente, varias se destacan no solo por preferir el romance placentero a la pasión, sino por «huir del ruidoso amor», como sugiere el título de un libro del filósofo francés François Jullien, para aproximarse a un discurso de lo «íntimo».

Si bien la enunciación bisexual de Delmira abre una vía fecunda para la enunciación lírica femenina, tal vez los «dos cisnes manchados [. . .] en el hotel de los sueños ajenos» metaforice un camino menos apropiado para hablar de un tema inevitable ya que «siempre hay / un amado». En suma, Kamenszain tiene que remitir a otros modelos para abrirse paso hacia una poética del amor que evite los escollos del sentimentalismo y del tono trágico y para que se escuche la voz de un sujeto en primera persona que no coincida completamente con la dicción autobiográfica y sin embargo nos sitúe en una zona de «lo íntimo». A partir de esta doble referencia -Teresa, Delmira - ¿cómo hablar del amor, de la pena de amor, del desgarro del amor sin caer en lo anacrónico (Teresa), lo melodramático (Delmira)? En primera instancia, Tango bar parece responder a esta pregunta a partir de la reescritura irónica del tango para desarmar su alcance machista y su "pesadumbre». ${ }^{38}$ El sujeto de la enunciación se escucha en la distancia que media entre el intertexto popular y su desarme operado por la puesta a distancia del yo poético. Pero la ironía, como enunciación que niega el enunciado, no consolida positivamente una voz de mujer que ocupe su lugar en el intercambio amoroso. Al contrario, la última referencia intertextual va a permitir que se afirme la singularidad de la voz femenina.

37 «El proceso lento, extenso y gradual del cortejo victoriano se ve reemplazado por una perspectiva más orientada hacia el presente. Es más, como los obstáculos formaban parte integral de dicho cortejo el dolor se consideraba intrínseco al proceso de conocimiento y a la construcción de la pareja, casi por definición. Y el dolor es precisamente aquello que se elimina de manera lenta pero segura del lenguaje correspondiente al amor hedonista. En la medida en que el placer y las emociones intensas se transforman en características supremas de la experiencia romántica, el dolor, los obstáculos y las dificultades, asociados hasta entonces de modo inevitable y necesario con el amor, se convierten en elementos inaceptables y, sobre todo, incomprensibles. La 〈densidad del amor comienza a disolverse en el aire del consumo, el ocio y el placer» (Eva Illouz: El consumo de la utopía romántica. El amor y las contradicciones culturales del capitalismo. Madrid/Buenos Aires: Katz 2009, p. 78).

38 Tamara Kamenszain: La novela, p. 259. 


\subsection{T.S. Eliot o la «experiencia incomunicable»}

De hecho, Tango bar parece cerrarse con una derrota, no la de la poesía que se escribe, pase lo que pase, sino la de un empuje vital hacia una nueva posibilidad de decir 〈yo〉 en un discurso de/sobre el amor que no sea irónico, que no se niegue a sí mismo diciéndose. Véanse las dos últimas estrofas del último poema:

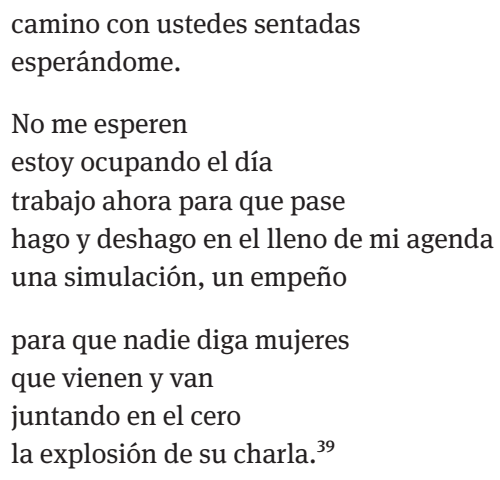

Estos versos finales vienen a dar una vuelta de tuerca a la construcción intertextual del poemario y, de paso, a la asociación entre escritura poética y oralidad femenina. De hecho resulta difícil no interpretar los versos «para que nadie diga mujeres / que vienen y van» como una reescritura de un estribillo que escande un poema famoso de T. S. Eliot. Así reza el dístico que se repite dos veces en «The Love Song of J. Alfred Prufrock»: «In the room the women come and go / Talking of Michelangelo». ${ }^{40}$

Recordemos rápidamente que el meollo de este poema es «la dificultad en la toma de la palabra ${ }^{41}$ por parte del hablante masculino que no se atreve a zanjar dos preguntas que se entrechocan insidiosamente: ¿hacer o no hacer el amor?; ¿decir o no decir el amor? El hablante lírico descorazonado deduce que no le es posible performar su masculinidad (es la tesis de Clifton) en una respuesta afirmativa a esta pregunta, lo que le habría permitido destacarse de las conversaciones ineptas de las mujeres que vagan a su alrededor. "It is imposible to say just what I mean!». ${ }^{42}$ Como concluye O’Connor: «De ahora en adelante, la experiencia en sí ya no es comunicable». ${ }^{43}$

39 Ibid., p. 261.

40 T. S. Eliot: La terre vaine et autres poèmes. Paris: Seuil 2014, p. 10, 12.

41 Mary E. O’Connor: «Parodie et histoire littéraire : lecture de The Love Song of J. Alfred Prufrock de T. S. Eliot». In: Études littéraires 19, 1 (1986), p. 126.

42 T. S. Eliot: La terre, p. 16.

43 Mary E. O’Connor: «Parodie», p. 130. Mi traducción. 
La reescritura de Kamenszain se opone in extremis a esta conclusión ya que ella rechaza tal imposibilidad: la poeta va a «trabajar» para que «nadie diga mujeres/que vienen y van». Las que hablan del amor son estas mujeres sentadas en un bar, lugar del tango y de la charla ruidosa ; pero la hablante se separa del grupo de mujeres habladoras, huyendo de lo que Jullien llama la equivocidad del amor ${ }^{44}$ en busca de la ambigüedad de lo íntimo, que rechaza todo dualismo y es reacio al relato del que gusta tanto el amor: «Se ha sacrificado tanto al Amor porque se presta a las peripecias de la intriga, dice Jullien, porque el relato del amor es cautivador y sus palabras sonoras - mientras que el progreso de lo íntimo es discreto». ${ }^{45} \mathrm{Al}$ final de Tango bar, queda claro para el lector que la hablante no quiere sacrificar ningún verso más al Amor, con A mayúscula, pero es cierto también que los poemarios siguientes no dejarán de ahondar en la experiencia del amor, propia y ajena como si hubiera que huir del «ruidoso amor» y de la retórica sentimental tanto del tango como del relato, de la puesta en intriga de lo que se perfila cada vez más como un drama de amor ${ }^{46}$ sin dejar de buscar el lugar de intersección entre la experiencia del amor y el lenguaje poético.

\section{Solos y solas (2005): la aporía del discurso amoroso}

En Solos y solas, el título parece enfatizar el carácter aporético de la búsqueda amorosa de la hablante, lo que refuerza también un epígrafe de Osvaldo Lamborghini. Señalemos primero que es muy significativo el nombre de Osvaldo Lamborghini, este padre secreto de los poetas argentinos según la propia Kamenszain. ${ }^{47}$ Aquí va el fragmento citado como epígrafe:

Sé lo que digo:

no puedo hablar de amor

44 Jullien opone lo equívoco del amor con la ambigüedad de lo íntimo que rehúsa todo dualismo (carne/espíritu, etc.) (François Jullien: De l’intime. Loin du bruyant Amour. Paris: Grasset 2013, p. 200-203).

45 François Jullien: De l'intime, p. 203.

46 Véase el poema sobre el alcoholismo del amante en Vida de living, del que Tamara entrega una interpretación en El libro de Tamar.

47 «Desde el hermetismo hasta la más extrema transparencia, desde el trabajo metafórico hasta la arbitrariedad metonímica, desde la rima hasta el hartazgo de la cadena narrativa: cuidado con escribir después de Lamborghini porque él ya fatigó todos los conductos» (Tamara Kamenszain: Historias, p. 118). 


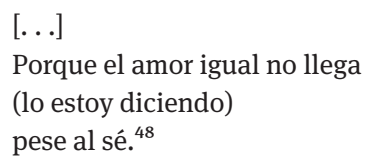

Lamborghini afirma aquí tanto la espera inevitable del amor como la imposibilidad del discurso amoroso. Más allá de todo lo que separa las poéticas de Osvaldo Lamborghini y Tamara Kamenszain, en esta oposición entre discurso (sobre el amor) y acontecimiento (de la experiencia amorosa), encuentro una fugaz pauta de lectura que podrían compartir estos dos escritores. En otras palabras, esta cita de Lamborghini le sirve a Tamara para resaltar el carácter irrenunciable de una poesía amorosa. Aunque rechace todo discurso sobre el amor concebido como relato y (melo)drama, le interesa la búsqueda de un lenguaje que logre plasmar la temporalidad intempestiva del amor como «presente», y no sólo como espera y memoria. Solos y solas expresa el tiempo de la espera, de la posibilidad del amor desde la conciencia aguda de no poder «hablar de amor» en presente, como consta en la última estrofa del libro:

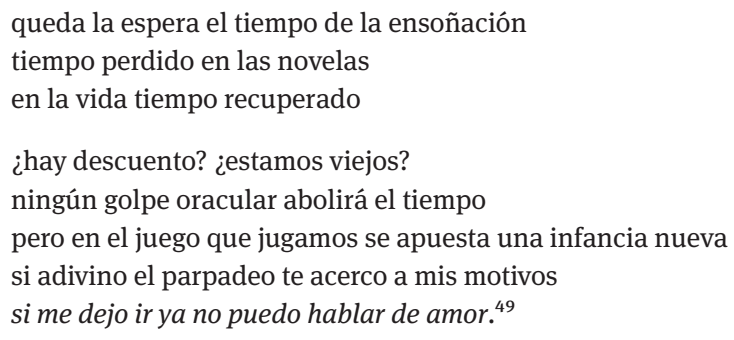

En un artículo sugerente, María Lucía Puppo ha analizado esta imposibilidad de hablar de amor y de vivir el amor en presente como un efecto del contexto urbano acelerado de la Buenos Aires desmemoriada de los años 90. La «cenicienta en radiotaxi $\rangle^{50}$ se cruza con hombres que ya no hacen soñar en el amor romántico: son «muñecos de aserrín» que «acoplan a la orquesta la letra de su anonimato». ${ }^{51}$ Si tomamos en consideración el conjunto del poemario, esta imposibilidad de «hablar de amor» se podría leer como una conclusión casi lógica de una poética que está buscando una «verdad», no estrictamente biográfica, sino una verdad

48 Osvaldo Lamborghini citado en Tamara Kamenszain: La novela, p. 315.

49 Tamara Kamenszain: La novela, p. 332. La cursiva es nuestra.

50 María Lucía Puppo: «Crisis, deconstrucción y empatía: la semiosis del espacio urbano en la poesía argentina reciente». In: Revista Chilena de Literatura 77 (2010), p. 309.

51 Ibid., p. 308. 
que tenga que ver con su devenir-sujeto pero que sea potencialmente mucho más amplia. Estos elementos dispersos cobran mayor sentido cuando se leen a la luz del pensamiento de Alain Badiou.

Badiou desarrolla una reflexión sistemática que reivindica la verdad como núcleo y foco de la empresa filosófica pero defiende una concepción de la verdad como plural por naturaleza: su premisa radica en «la declaración de que hay verdades» sin que esto implique un saber acerca de la verdad. La filosofía destaca cuatro «condiciones», o sea cuatro procedimientos productores de verdades que les son propias: el amor, el arte [la poesía], la política y las ciencias [las matemáticas]. La tarea de la filosofía no consiste en producir verdades sino en elaborar el discurso que permite aprehender su composibilidad, es decir, cómo estas verdades esbozan el rostro polifacético y al mismo tiempo unificado de una época. La noción de acontecimiento es central en el pensamiento de Badiou ya que es lo que opera el surgimiento de una verdad que anteriormente no habría podido discernirse. El encuentro y la declaración de amor posterior constituyen en ese sentido un acontecimiento que articula la disyunción fundamental de los amantes según la que «Nada en la experiencia es lo mismo para la posición hombre y para la posición mujer»; $;^{52}$ «No existe una tercera posición». ${ }^{53}$ No hay pues ninguna perspectiva abarcadora que permita observar la disyunción que separa las dos posiciones (hombre/mujer). Es precisamente por esta razón, que «la experiencia del sujeto amante, que es la materia del amor, no constituye ningún saber acerca del amor. [. . .] El amor, como experiencia del pensamiento, se impiensa». ${ }^{54}$ No habría saber, no habría posibilidad de hablar auténticamente del amor desde la experiencia misma. La aporía del discurso amoroso en la poesía de Kamenszain traduciría la conciencia aguda que tiene la poeta de esta imposibilidad.

\section{Escritura en prosa y desciframiento retrospectivo de la experiencia amorosa}

La pregunta que se plantea ahora es la de saber si esta aporía del discurso poético amoroso - tan inevitable como necesario- se debe a la constricción del género. En otros términos, cabe preguntarse si la prosa ensayística podría esclarecer lo que le está vedado al poema. Como siempre con Kamenszain, la respuesta no

52 Alain Badiou: Conditions. Paris: Seuil 1992, p. 257. Traducción nuestra.

53 Ibid., p. 258. Traducción nuestra.

54 Ibid., p. 257. Traducción nuestra. En francés como en español, el último verbo es un neologismo («L'amour, comme expérience de la pensée, s’impense»). 
es tan evidente como parece. Llama la atención la casi contemporaneidad entre Tango bar (1998) y una serie de ensayos precisamente titulados Historias de amor (y otros ensayos sobre poesía). Este libro publicado en 2000 se abre con un prólogo y un epígrafe de Kristeva: «El amor es algo de lo que se habla y no es más que eso. Los poetas siempre lo han sabido». ${ }^{55}$ Los ensayos presentes en el libro y ordenados por estado civil («La divorciada. . .», «La soltera. . .», «La viuda», «El cónyuge. . .», etc.) parecen indicar igualmente la necesidad de una lectura irónica del epígrafe de Kristeva: no hay experiencia amorosa alcanzable en el lenguaje y los poetas, quienes conocen este secreto a voces, arman el trampantojo del poema de amor: acotan el lugar del amor sin aprehenderlo. El contexto de esta misma cita de Kristeva aparece en el texto dedicado a Oliverio Girondo y la ensayista destaca ahí el valor paródico que le otorga Girondo al tópico amoroso en poesía. Sin embargo, a continuación, la ensayista evoca un juego amoroso en la pareja de escritores: Oliverio Girondo y Norah Lange se escribían mutuamente «encargos». Así Oliverio le dedica a Norah el poema «Ángelnorahcustodio», lo cual «es el apellido que le da Girondo a la autora que puso en Personas en la sala la firma Lange. Un ángel visto en anagrama». ${ }^{56}$ En Historias de amor, Kamenszain, como crítica de la poesía, parece desentenderse tanto de la propia biografía como de su trayectoria poética, en un afán por dilucidar la relación entre el hablante lírico, el tópico amoroso (con su inevitable proyección biográfica) y la exploración lingüística a la que se entrega Girondo.

Ahora bien, leídos a la luz del libro de Kamenszain publicado en 2018, estos comentarios sobre Girondo/Lange nos dan la impresión de apuntar a otra pareja de escritores cuya sombra seguramente recorre ya las páginas de Historias de amor: una pareja que Kamenszain formaba con Héctor Libertella y que por esos años estaba atravesando una honda crisis. En efecto, El libro de Tamar (2018) gira alrededor de un poema breve que su ex-marido, el escritor Héctor Libertella, deslizó debajo de su puerta muy poco tiempo después de su separación. El poema consiste en una yuxtaposición de anagramas a partir del nombre Tamar. Tal vez se trate de un homenaje poético a la tradición cultural judía a la que pertenece Kamenszain, más concretamente la Cábala, cuya hermenéutica se basaba profusamente en las posibilidades semánticas brindadas por los distintos tipos de combinatoria de las letras hebreas. ${ }^{57}$ El ensayo de crítica literaria ha dado

55 Julia Kristeva: Histoires d'amour. Paris: Denoël 1985, p. 14.

56 Tamara Kamenszain: Historias, p. 61.

57 Recordemos brevemente que el anagrama (asociado con lo que los cabalistas llaman «temurá») figura entre los tres procedimientos básicos de desciframiento del sentido oculto de la Torá al lado de la gematría (que realza el valor numérico de las letras) y del notaricón (que realza su disposición a la manera de un acróstico). 
paso aquí a la prosa narrativa, que combina recuerdos autobiográficos y generacionales, así como evocaciones de otras parejas de escritores; en este relato se engastan algunas veces unos poemas. Escrito en julio del 2000, el poema de Libertella funciona como una matriz memorística y hermenéutica. La escritura de Kamenszain ha roto con el poema que apuesta por la posibilidad futura de escribir la experiencia amorosa (cf. el final de Tango bar y Solas y solas); ahora se entrega al gozo melancólico de recordar el amor, encontrando el camino de cresta que siempre había buscado al evitar el escollo tanto del pathos como de la ironía.

Al comentar el hallazgo del poema de Libertella en el fondo olvidado de un cajón, la autora asevera: «Tuvieron que pasar quince años [...] para que me diera cuenta de que era posible llegar a leerlo en clave amorosa». ${ }^{58}$ Lo que dilucida $E l$ libro de Tamar es que la reconciliación entre la experiencia amorosa y el poema no resulta de una intención autorial sino que constituye un efecto de lectura, condicionado por una temporalidad que fluye de forma desigual. ${ }^{59}$ Desde esta perspectiva, El libro de Tamar se puede considerar como una explicitación meticulosa del cambio que ha afectado su manera de leer el poema de Libertella. Hacia el final, la autora declara: «A esta altura y después de darles vuelta a tantos y tantos bolsones semánticos, ya lo estoy empezando a leer como un genuino poema de amor». ${ }^{60}$ Mientras que Tango bary Solos y solas realzaban el problema de la enunciación del amor que no encuentra sino formas gastadas, inauténticas, El libro de Tamar invierte la perspectiva al poner en escena el poema de amor como efecto de lectura. Leer ese poema como poema de amor va a desembocar en un ejercicio de memoria, que no es indagación nostálgica en el pasado. Además, aunque contenga poemas, el libro no es un poemario: es un ensayo en prosa que junta fragmentos en un orden casi concéntrico: giran alrededor del nombre «Tamar», título del primer y último fragmento del libro. ¿Qué significa el énfasis en ese nombre que abre y cierra el libro y le da su título?

Una primera aproximación a esta pregunta podría estribar en la hipótesis siguiente: El libro de Tamar elabora un trabajo de duelo. Para retomar la terminología de los psicoanalistas Abraham y Torok, El libro de Tamar lleva a cabo un trabajo de introyección, esto es, lleva a reconocer que la pérdida afectó al yo y que para «tragar» esa pérdida, hay que aceptar que el yo no salió indemne, perdió

58 Tamara Kamenszain: El libro de Tamar. Buenos Aires: Eterna Cadencia 2018, p. 15.

59 Un mecanismo temporal similar rige la reedición de El texto silencioso (1983) que la autora incluye al final de sus Historias de amor. La relectura del ensayo de juventud modifica la percepción del ensayo más reciente: «agujerea las Historias de amor con muerte y con silencio» (Tamara Kamenszain: Historias, p. 12).

60 Tamara Kamenszain: El libro, p. 81. 
algo de sí. De no ser así, pueden manifestarse síntomas de incorporación: guardar el objeto aparte, evitar todo proceso de cambio. ¿Cómo no pensar en ello al constatar que Kamenszain guardó durante quince años una página A4 en el fondo de un cajón sin querer ver en él una señal de algo que se parece al amor, sin poder leerlo «en clave amorosa»? Lo que el sujeto acepta perder en El libro de Tamar es precisamente la «historia de amor». Hay un comienzo nítido pero el final se desdibuja: ni final trágico (H. Libertella muere varios años después de la separación sin que ella sea responsable), ni final feliz (se separaron). Tampoco se perdió completamente el «afecto», la «amistad» o cariño», palabras que se mencionan en el libro para hablar de las relaciones que siguieron uniendo a los ex esposos. La historia se desarma, Kamenszain no puede, como Kristeva, escribir una novela para expresar su «experiencia interior». ${ }^{61}$ Lo que la indagación hermenéutica de la autora argentina termina realzando es la forma nueva de ser llamada. Tamar: es un nombre a medio camino entre lo más público (como su nombre quedó anotado oficialmente cuando nació) y lo más íntimo (la nota de Libertella). El amor entre ambos parece haber existido no como historia sino como enunciación:

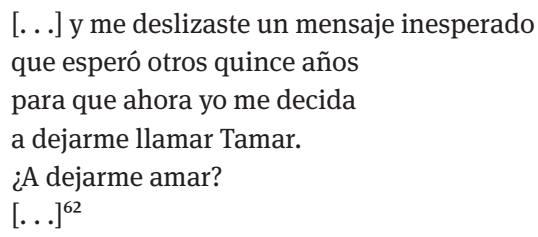

Los palíndromos y anagramas de Héctor tienen una virtud iniciática y casi terapéutica. Acoger ese nombre como un «presente» y responder con otro presente, el libro: este es el intercambio de dones que se despliega en El libro de Tamar. El presente del poema, engastado en este peculiar ejercicio de análisis poético autobiográfico, renuncia definitivamente a «armar una trama», ${ }^{63}$ pero sí abre una temporalidad diferente en la que Héctor Libertella puede volver a ser el «contemporáneo» de Tamara Kamenszain. ${ }^{64}$

61 Tamara Kamenszain: El libro, p. 39.

62 Ibid., p. 36.

63 Véanse el primer verso del poema de Libertella («Arma trama, Ama») y el título del tercer capítulo: «Arma trama».

64 Kamenszain evoca el destino editorial de un texto de Libertella para Ludmer que esta publica póstumamente: «aparece como la última de las sucesivas capas que reconstruyen o rearman una trama de amistad en la que Héctor, Josefina, yo o algunos otros nos vamos haciendo presentes» (Tamara Kamenszain: El libro, p. 72). Además la autora cita a Ludmer quien asevera: «En la memoria intima-pública de la ciudad todos somos contemporáneos» (Ibid., p. 73). 
El abandono de la «trama» (otro anagrama de Tamar), o sea, la imposibilidad de contar la historia de amor en el poema sin desvirtuarla, ya nos estaba anunciada en el epígrafe del libro firmado por Mark Strand: «Fui tocado por mi propia soledad mientras leía sabiendo que lo que siento es a menudo la cruda y desafortunada forma de una historia que quizás nunca sea contada». ${ }^{65}$ Este epígrafe formula la ecuación lograda por El libro de Tamar. Por un lado, el / la poeta siente la «desafortunada forma de una historia que quizás nunca sea contada»: la historia de amor es una forma que pugna inútilmente por plasmarse. Aparece para que la escritora pueda lograr «separarse de esta historia». ${ }^{6}$ Por otro lado, este movimiento que busca concretarse abre una perspectiva incierta hacia el futuro, como marca de la carencia y del deseo. Pero tanto para Strand como para Kamenszain, el presente de la escritura es otro: «Fui tocado por mi propia soledad mientras leía». En otros términos, para ambos escritores, la lectura se convierte en acontecimiento y revelación. De la misma índole resultó ser la lectura postergada del poema de Libertella, rastro de un «sueño con la máxima cantidad de anagramas y combinaciones de tu nombre». ${ }^{67} \mathrm{~A}$ la experiencia viva del amor, no le corresponde en el ámbito del poema «la historia de amor»: esta anularía la experiencia amorosa como «condición» de surgimiento de una verdad (en la perspectiva de Badiou). La dimensión de acontecimiento del amor se recoge más bien en un momento determinado de la lectura: aquí resulta sintomático que el texto se pueda leer como poema de amor cuando el duelo ha operado la separación de los amantes en el seno de una memoria apaciguada. De ahí que la lectura del poema como poema de amor sea inseparable de una dinámica anímica que el texto en prosa reconstruye, un texto escandido por poemas engastados en él como piedras preciosas.

\section{Bibliografía}

Abraham, Nicolas y Maria Torok: L'écorce et le noyau. Paris: Flammarion 1996.

Agustini, Delmira: Los cálices vacíos, ed. e intr. Rosa García Gutiérrez. Sevilla: Point de Lunettes 2013.

Badiou, Alain: Conditions. Paris: Seuil 1992.

Butler, Judith: Mecanismos psíquicos del poder. Teorías sobre la sujeción, trad. Jacqueline Cruz. Madrid: Cátedra 2001.

65 Tamara Kamenszain: El libro, p. 9.

66 Ibid., p. 84.

67 Ibid., p. 11. 
Clifton, Brian: «Textual Frustration: The Sonnet and Gender Performance in «The Love Song of J. Alfred Prufrock»». In: Journal of Modern Literature 42, 1 (2018), p. 65-76.

Demers, Jeanne: «Présentation. En liberté, la poétique». In: La poétique de poète. Etudes françaises 29, 3 (1993), p. 7-15. https://id.erudit.org/iderudit/035924ar [Consultado el 10 de mayo 2020].

Eliot, T. S.: La terre vaine et autres poèmes, edición bilingüe, trad. P. Leyris. Paris: Seuil 2014.

Fernández, Nancy: «Entrevista a Tamara Kamenszain». In: Revista Iberoamericana 261 (2017), p. 737-741.

Genovese, Alicia: La doble voz: Poetas argentinas contemporáneas. Buenos Aires: Biblos 1998.

Illouz, Eva: El consumo de la utopía romántica. El amor y las contradicciones culturales del capitalismo. Madrid/Buenos Aires: Katz 2009.

Jullien, François: De l'intime. Loin du bruyant Amour. Paris: Grasset 2013.

Kamenszain, Tamara: Historias de amor (y otros ensayos sobre poesía). Buenos Aires: Paidós 2000.

-: La novela de la poesía. Buenos Aires: Adriana Hidalgo 2012.

-: «Epílogo». In: R. Echavarren, J. Kozer y J. Sefamí (eds.): Medusario: Muestra de poesía latinoamericana, p. 421-422. Santiago de Chile: AErea 2016.

-: El libro de Tamar. Buenos Aires: Eterna Cadencia 2018.

Kristeva, Julia: Histoires d'amour. Paris: Denoël 1985.

León, Denise: «La mirada de Ruth. Fabulaciones del linaje en la poesía de Tamara Kamenszain». In: Anales de Literatura Hispanoamericana 38 (2009), p. 341-352.

León, Fray Luis de: De los nombres de Cristo, ed. C. Cuevas. Madrid: Cátedra 1986.

O’Connor, Mary E: «Parodie et histoire littéraire : lecture de The Love Song of J. Alfred Prufrock de T.S. Eliot». In: Études littéraires 19, 1 (1986), p. 125-138. https://doi. org/10.7202/500745ar.

Peluffo, Ana: «'De todas las cabezas quiero tu cabeza»: figuraciones de la femme fatale en Delmira Agustini». In: Chasqui 34, 2 (2005), p. 131-144.

Perlongher, Néstor: «Introducción a la poesía neobarroca cubana y rioplatense». In: Revista Chilena de Literatura 41 (1993), p. 47-57. http://www.jstor.org/stable/40356678 [Consultado el 14 de mayo 2020].

Puppo, María Lucía: «Crisis, deconstrucción y empatía: la semiosis del espacio urbano en la poesía argentina reciente». In: Revista Chilena de Literatura 77 (2010), p. 109-125.

Teresa de Jesús, Santa: Obras completas, ed. Efrén de la Madre de Dios y Otger Steggink. Madrid: BAC 1986.

Vasse, Denis: L'autre du désir et le Dieu de la foi: lire aujourd'hui Thérèse d'Avila. Paris: Seuil 1991. 
